\title{
Clinical Evaluation of an Essential Oil Intraoral Spray for Treatment of Dry Mouth
}

\author{
Vaishali Balyan ${ }^{1}$, Mahantesha S², Vedika Talwar ${ }^{3}$, Sugandha Mishra ${ }^{4}$, Sneha Joseph ${ }^{5}$
}

\begin{abstract}
Aim: To assess the effect of essential oil intraoral spray for dry mouth. Composition of spray: essential oil (peppermint oil $1 \mathrm{~mL})$, propolis (1.5 mL), xylitol $(700 \mathrm{mg}$ ), ethyl alcohol (10 mL), and water (up to $50 \mathrm{~mL}$ ).

Materials and methods: A total of 30 patients with dry mouth symptoms were selected for the study (study group). Clinical parameters such as gingival index, plaque index, and visual analog scale (VAS) for xerostomia and desensitization were recorded. A total of 30 patients were selected for control group. Two intraoral sprays were formulated one for each group. The results of both groups were then analyzed.

Results: Statistical difference was obtained in the various parameters between the two groups. Mean gingival index (Gl) score in control group at baseline was found to be $0.489+1.242$ and postoperative it was $0.271+0.109$. There was a statistically significant difference in mean $\mathrm{Gl}$ score between baseline and postoperative at $5 \%$ significance level $(p=0.001)$.

Mean salivary rate (SR) score in control group at baseline was found to be $2.400+1.242$ and postoperative it was $2.066+0.961$. There was no statistically significant difference in mean SR score between baseline and postoperative at $5 \%$ significance level $(p=0.298)$.

Conclusion: Essential oil and propolis spray are effective in improving oral health of patients suffering from dry mouth and dentinal hypersensitivity. It also ensured better patient compliance. Hence, encouraged them to use as prescribed.

Clinical significance: Essential oil intraoral spray has all the advantages of promoting oral health by treating xerostomia, dentinal hypersensitivity, and less plaque accumulation; thus, improving the overall health.

Keywords: Desensitization, Essential oil, Propolis, Xerostomia.

World Journal of Dentistry (2022): 10.5005/jp-journals-10015-1916
\end{abstract}

\section{INTRODUCTION}

Dry mouth is also called "Xerostomia." It happens when the body's salivary glands do not make enough saliva to keep the mouth moist. Saliva is needed for chewing, swallowing, tasting, and talking. A dry mouth can make these activities difficult and uncomfortable. Xerostomia refers to the subjective sensation of a dry mouth; it is frequently but not always associated with salivary gland hypofunction. There are various factors which are responsible for Xerostomia.

These include, due to developmental origin (salivary gland aplasia), due to water loss (impaired fluid intake, hemorrhage, vomiting/diarrhea), due to iatrogenic origin (medications, radiation therapy to the head and neck, chemotherapy), due to systemic diseases (Sjogren syndrome, diabetes mellitus, diabetes insipidus, sarcoidosis, HIV infection, hepatitis infection, graft vs host disease, psychogenic disorders), local factors (decreased mastication, smoking, and mouth breathing).

Xerostomia is a common problem that has been reported in $25 \%$ of older adults. Earlier it was thought that dry mouth in older patients was because of aging. However, it is now accepted that any reduction in salivary function associated with age are modest and are not associated with any significant reduction in salivary function. Instead, in older adults it is more likely the result of other factors such as, medications. Not only the specific drugs are known to produce the dry mouth, but the prevalence of xerostomia also increases in relation to the total number of drugs that a person takes, regardless of whether the individual medications are xerogenic or not. Treatment of xerostomia includes medications such as mucosal lubricants, saliva substitutes, and saliva stimulants (systemic sialogogues like pilocarpine and cevimeline), however,
${ }^{1,3-5}$ Faculty of Dental Sciences, MS Ramaiah University of Applied Sciences, MSR Nagar, Bengaluru, Karnataka, India

${ }^{2}$ Department of Periodontology, Faculty of Dental Sciences, MS Ramaiah University of Applied Sciences, MSR Nagar, Bengaluru, Karnataka, India

Corresponding Author: Vaishali Balyan, Faculty of Dental Sciences, MS Ramaiah University of Applied Sciences MSR Nagar, Bengaluru, Karnataka, India, Phone: +1289-707-5373, e-mail: vaishalibalyan96@gmail.com

How to cite this article: Balyan V, Mahantesha S, Talwar V, et al. Clinical Evaluation of an Essential Oil Intraoral Spray for Treatment of Dry Mouth. World J Dent 2022;13(2):110-115.

Source of support: Nil

Conflict of interest: None

these drugs have many side effects; excessive sweating, cutaneous vasodilatation, emesis, nausea, diarrhea, persistent hiccup, bronchoconstriction, hypotension, bradycardia, increased urinary frequency, and vision problems. Several treatment strategies for the management of xerostomia are available since many years and they all aim to reduce patients' symptoms and/or increase salivary flow. The treatment of xerostomia is difficult, and unsatisfactory most of the times. Artificial salivas are available and may make the patient feel comfortable, as is done by the continuous sips of water throughout the day. Also, sugarless candy can be used to stimulate the salivary flow. Other management approaches include the use of oral hygiene products that contain lactoperoxidase, lysozyme, lactoferrin (e.g., biotene tooth paste and mouthrinsense,

() The Author(s). 2022 Open Access This article is distributed under the terms of the Creative Commons Attribution 4.0 International License (https://creativecommons. org/licenses/by-nc/4.0/), which permits unrestricted use, distribution, and non-commercial reproduction in any medium, provided you give appropriate credit to the original author(s) and the source, provide a link to the Creative Commons license, and indicate if changes were made. The Creative Commons Public Domain Dedication waiver (http://creativecommons.org/publicdomain/zero/1.0/) applies to the data made available in this article, unless otherwise stated. 
oral balance gel). If patient's medication is the cause of dry mouth, then discontinuation of the drug should be done. Pilocarpine can also be used for the treatment of xerostomia however, it has some serious side effects such as excess sweating, increased heart rate, and blood pressure.

Various side effects of drugs and no availability of any natural product in the market for the treatment of xerostomia motivated the research for the development of a spray whose ingredients not only help in treating xerostomia but also has added benefits of treating dentinal hypersensitivity and control of plaque. Additionally, there are various mouthrinses available but there is no availability of any spray. Motive behind the development of spray is that it can used anywhere and anytime unlike mouthrinses which requires water, and you cannot use it in the public.

Dentin hypersensitivity is one of the most occurring dental problem and is also the least successfully treated. Supragingival dental plaque is a major factor in the initiation of caries and gingivitis. Mechanical removal of dental plaque is the most common method of plaque control. ${ }^{1}$

In chemical plaque control, chlorhexidine is still the gold standard for its antimicrobial action with high substantiveness but has side effects such as pigmentation and taste alteration. ${ }^{2}$

Several clinical studies have demonstrated that essential oil-containing mouthrinse can combat harmful bacteria and improve oral health. ${ }^{3}$ It has been effective in controlling plaque and gingivitis. They kill microorganisms by destroying the cell walls and inhibiting their enzymatic activity. ${ }^{4}$

Many biological activities have been reported for propolis such as antimicrobial, anti-inflammatory, and antioxidants. Hence, this study determines the antiplaque and desensitization effect of propolis and essential oil in vivo. These are the reasons for selecting the peppermint oil and propolis.

The herb peppermint is a cross between two types of mint (water mint and spearmint). Essential oil obtained from peppermint is used for various health purposes. Peppermint oil is said to have the properties of stimulating salivary secretion. Propolis which is a resinous product that is collected from plants by bees. Propolis has potent antibacterial and anti-inflammatory properties. Propolis has been used therapeutically by humans for centuries, including the treatment of dental caries and mouth infections.

Aim of the study was to assess the effect of essential oil intraoral spray for dry mouth. Main objectives included assessment of amount of saliva secretion, evaluation of antiplaque effect of the intraoral spray and assessment of reduction of dentinal hypersensitivity.

\section{Materials and Methods}

Our study was designed as a nonrandomized clinical study involving 30 volunteers, with sample size of 30 to evaluate the efficacy of essential oil intraoral spray over control spray.

The essential oil (peppermint oil) was commercially obtained from the pharmacology lab at Ramaiah University. This study was conducted in Department of Periodontology, Faculty of Dental Sciences, Ramaiah University of Applied Sciences.

Composition for control and test spray are shown in Table 1. Preparation for the same is shown in Table 2.

The inclusion criteria of the study were 30 healthy volunteers with age group of 18 to 65 years. All subjects were screened for suitability by research team. It also included dentition with more than or equal to 20 valuable teeth and subjects with no severe periodontal disease, no oral lesions, removable prosthesis, no orthodontic bands, grossly decayed teeth, and no deep dental caries, subjects with no antibiotic coverage 3 months prior to commencement of study.

Study excluded the subjects who were allergic to any of the components of the spray. Chronic alcoholic and smokers were excluded from the criteria. Subjects with systemic problems were also not included in the study.

All eligible subjects were given oral information about the product and the purpose of the study. They were asked to sign an informed consent.

This study was designed as a nonrandomized clinical study involving 30 volunteers to compare two samples- essential oil spray and placebo.

The volunteers first received a thorough professional prophylaxis at the base line and each volunteer was refrained from all oral hygiene methods other than brushing. The subjects in the test group received a bottle containing an essential oil-based oral spray, whereas subjects in the control group received a bottle of pineapple flavored spray, each of them being unaware of the group which they belonged to (single blind study).

Volunteers were asked to use the given sample four times a day after food. They were instructed to spray two to three times at once straight onto their tongue and teeth.

Baseline data of the following indices were collected at the beginning of the study. Volunteers were assessed at an interval of 2 weeks and the indices were recorded in both the groups at the end of 4 weeks. Only one examiner was chosen to eliminate the different ways of interpretation and to avoid any kind of variations when examined clinically.

Gingival index: Loe and Silness; Plaque Index: Silness and Loe; VAS scale: for hypersensitivity and dryness of mouth.

All volunteers received a questionnaire using a visual analog scale (VAS) designed to evaluate their attitudes with regards to the product used.

Xerostomia VAS scale: Subjects rated the following on a scale of 1 to 5 with 1 to not difficult and 5 to very difficult (As shown in Fig. 1).

- Rate the difficulty you experience in speaking due to dryness of mouth rate the difficulty you experience in swallowing due to dryness

Table 1: Composition for $50 \mathrm{~mL}$ of test and control

\begin{tabular}{ll}
\hline Test & Control \\
\hline 1. Essentialoil:peppermintoil-1mL & 1. Ethyl alcohol-10 mL \\
2. Propolis-1.5 mL & 2. Flavored water-2.5 mL \\
3. Xylitol-700 mg & 3. Xylitol-700 mg \\
4. Ethyl alcohol-10 mL & 4. Water-upto $50 \mathrm{~mL}$ \\
5. Water-upto $50 \mathrm{~mL}$ &
\end{tabular}

Table 2: Preparation of one bottle of test and control (50 mL each)

\begin{tabular}{|c|c|}
\hline Test & Control \\
\hline $1.5 \mathrm{~mL}$ propolis was dissolved in & $2.5 \mathrm{~mL}$ flavored water was added \\
\hline $\begin{array}{l}700 \mathrm{mg} \text { of xylitol was dissolved } \\
\text { in } 10 \mathrm{~mL} \text { of water and added to } \\
\text { above solution. }\end{array}$ & $\begin{array}{l}700 \mathrm{mg} \text { of xylitol was dissolved } \\
\text { in } 10 \mathrm{~mL} \text { of water and was added } \\
\text { to above prepared solution. }\end{array}$ \\
\hline $\begin{array}{l}1 \mathrm{~mL} \text { peppermint oil was added } \\
\text { to prepared solution and water } \\
\text { was added up to } 50 \mathrm{~mL} \text { mark. }\end{array}$ & $\begin{array}{l}\text { Water was added up to } 50 \mathrm{~mL} \\
\text { mark. }\end{array}$ \\
\hline
\end{tabular}




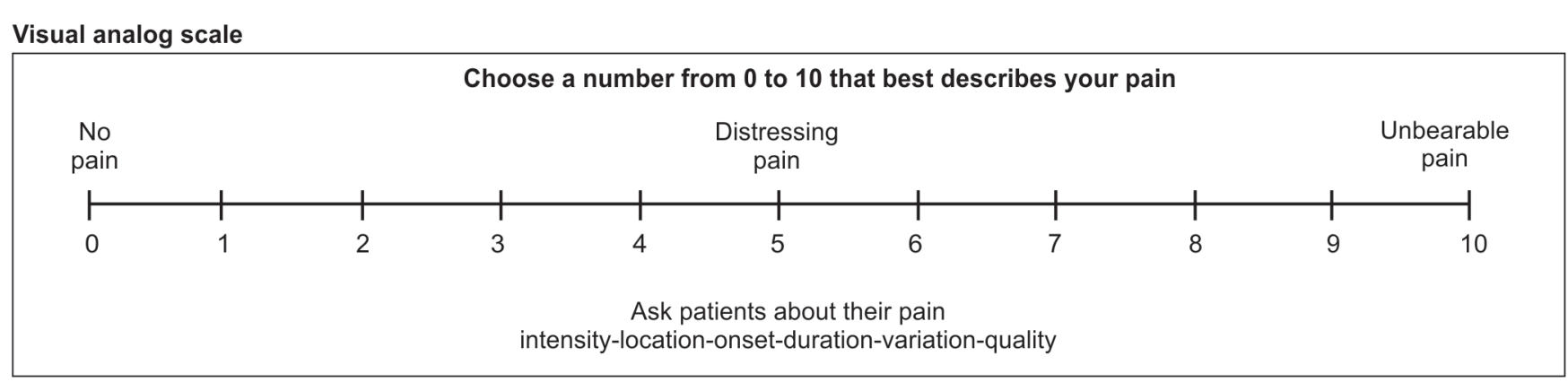

\section{"Faces" pain rating scale}

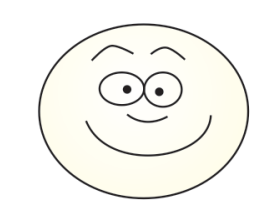

0

No hurt

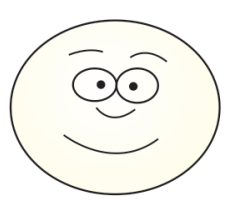

1

Hurts

little bit

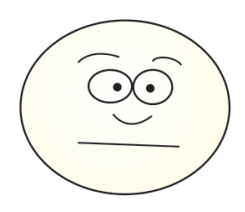

2

Hurts

little more

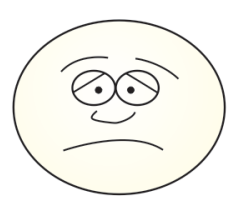

3

Hurts even more

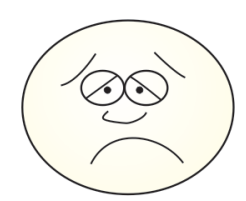

4

Hurts whole lot

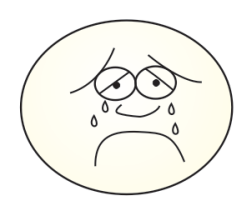

5

Hurts worst

Fig. 1: Hypersensitivity VAS scale

- Rate how much saliva is in your mouth rate the dryness of your mouth

- Rate the dryness of your throat rate the dryness of your lips

- Rate the dryness of your floor of the mouth rate the dryness of your tongue.

Outcome:

Our study has shown a mean plaque index of 0.292 postoperative as compared to baseline plaque index of 0.669 . Our study has shown greater reduction in plaque regrowth because of the added benefit of propolis.

Our study has shown desensitization index of 1.866 as baseline as compared to postoperative index of 0.533 in case group. However, our study has shown no difference in desensitization index (baseline and postoperative) in control group because of the absence of propolis in control spray. Hence, proving the role of propolis in treatment of dentinal hypersensitivity.

Salivary rate as scored by patient in accordance with VAS scale has shown baseline index of 2.066 and postoperative index of 1.733 .

In present study, mean gingival index score improvement was compared between case and control group using Mann-Whitney $\mathrm{U}$ test (Figs 2 to 5 ).

Mean Gl score improvement in control group was found to be $0.214+0.200$ and in case group it was $0.320+0.144$. There was a statistically significant difference in mean $\mathrm{Gl}$ score improvement between case and control group at $5 \%$ significance level $(p=0.045)$.

In present study, mean SR score improvement was compared between case and control group using Mann-Whitney $U$ test.

Mean SR score improvement in control group was found to be $0.333+0.723$ and in case group it was $0.333+0.985$. There was no statistically significant difference in mean SR score improvement between case and control group at $5 \%$ significance level ( $p=0.646)$.

\section{Outcome:}

In present study, mean gingival index score in control group and case group between base line and postoperative was compared using Wilcoxon Signed Ranks Test (shown in Tables 3 and 4 ).

Mean GI score $n$ control group at baseline was found to be 0.489 +1.242 and in postoperative it was $0.271+0.109$. There was a

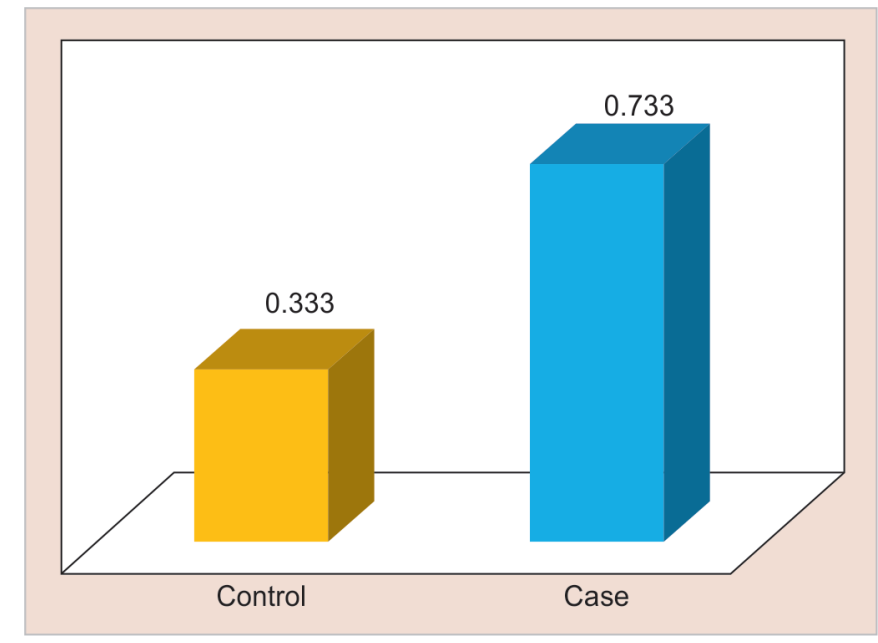

Fig. 2: Bar graph showing postoperative difference in dryness of mouth between case and control (according to Mann-Whitney U test). Improvement in the dryness of mouth was the outcome of the use of case intraoral spray as compared to control spray

statistically significant difference in mean GI score between baseline and postoperative at $5 \%$ significance level $(p=0.001)$.

Mean SR score in control group at baseline was found to be $2.400+1.242$ and in postoperative it was $2.066+0.961$. There was no statistically significant difference in mean SR score between baseline and postoperative at $5 \%$ significance level $(p=0.298)$.

\section{Discussion}

Xerostomia is not a disease but can be a symptom of certain diseases. It can have serious negative effects on a patient's lifestyle, dietary habits, nutritional status, speech, taste, and susceptibility to dental cari. Temporary causes of dry mouth include psychological, duct calculi, sialadenitis, etc. Although xerostomia often is a manifestation of impaired salivary gland function, it can occur with or without a noticeable decrease in saliva production. Symptoms of dry mouth may range from mild oral discomfort to significant 


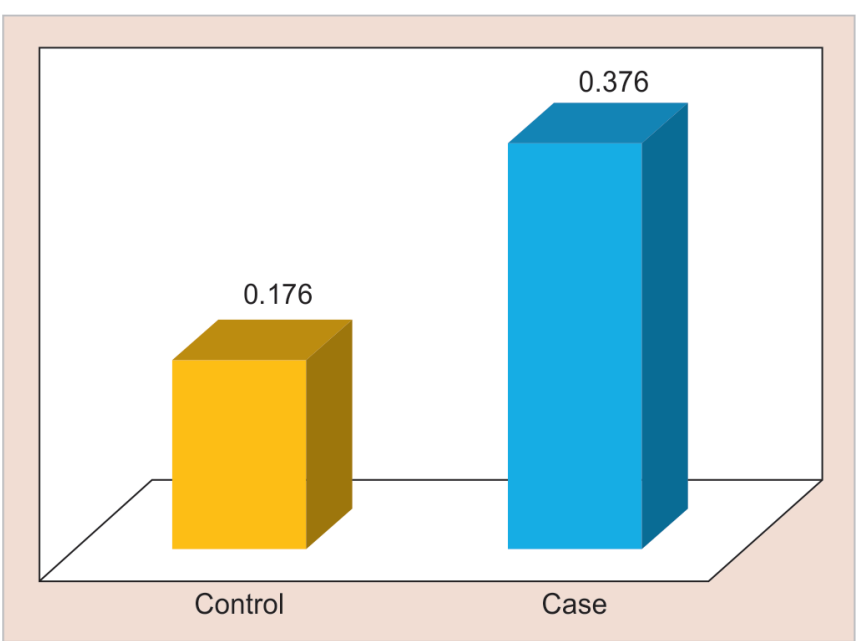

Fig. 3: Bar graph showing postoperative difference in plaque index between case and control (according to Mann-Whitney U test)

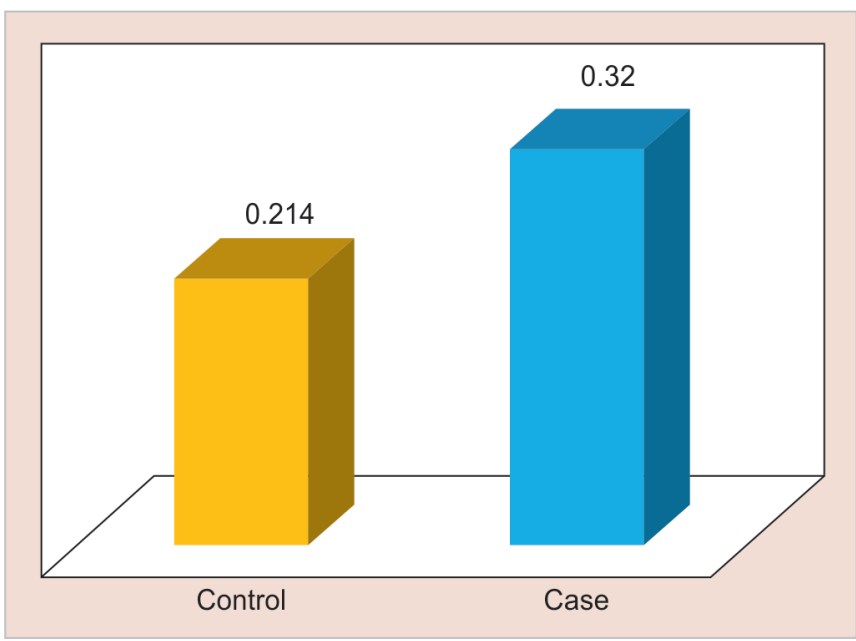

Fig. 4: Bar graph showing postoperative difference in gingival index between case and control (according to Mann-Whitney $\mathrm{U}$ test). There was a statistically significant difference in mean $\mathrm{Gl}$ score between baseline and postoperative at $5 \%$ significance level $(p=0.001)$

oral disease that can compromise patients' health, dietary intake, and quality of life. The basic principles of management that were already present were to eliminate the etiological factors such as drugs, calculi, and emotional problems. Sialogogues and various sugar free chewing gums are also available to promote salivary stimulation to treat xerostomia. Studies have shown that prevalence of xerostomia ranges from 0.9 to $64.8 \%$.

The purpose of present prospective study is to assess the effect of essential oil intraoral spray to relieve symptoms of dry mouth and improve oral health. This study had two sprays-Test and Control spray. Essential oils have been used for many years in the prevention and treatment of periodontal disease. Several studies have demonstrated that $\mathrm{EO}$ and $\mathrm{CHX}$ rinses were equally effective in reducing gingival index scores and the number of bleeding sites. ${ }^{5}$

The study was necessary for those patients who cannot tolerate the sialogogues or those who have psychological issues and don't want to use drugs for treating dry mouth. Maintaining adequate hydration is also important for patients with dry mouth. The spray increased the urge to drink water in the subjects which also aided

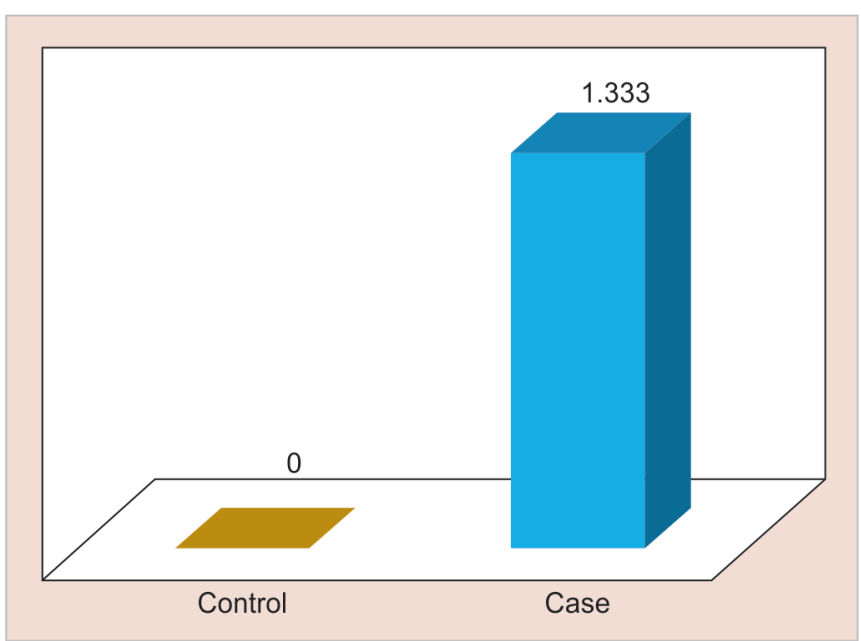

Fig. 5: Bar graph showing postoperative difference in densitization index between case and control (according to Mann-Whitney U test). It was determined that dental hypersensitivity improved in patients who were provided with the (case) spray

in providing relief to xerostomia. The study also emphasized on treating dentinal hypersensitivity with the use of propolis.

In our study, two mouth sprays were formulated, one experimental containing $\mathrm{EO}$ and propolis and pineapple flavored control. Test spray was composed of essential oil (peppermint oil $1 \mathrm{~mL})$, propolis $(1.5 \mathrm{~mL})$, xylitol $(700 \mathrm{mg})$, ethyl alcohol $(10 \mathrm{~mL})$, and distilled water (upto $50 \mathrm{~mL}$ ). Control spray was comprised of ethyl alcohol $(10 \mathrm{~mL}$ ), flavored water (pineapple flavor $2.5 \mathrm{~mL}$ ), xylitol $(700 \mathrm{mg}$ ), and water upto $50 \mathrm{~mL}$. The novel thing about the study was there is no such spray available which so handy to use and can treat dry mouth along with added benefits of treating dentinal hypersensitivity and to prevent the plaque formation.

The results were compared between the subjects and control. Subjects were reviewed at the end of 2 weeks and were assessed at the end of 4 weeks. All the indices included in the study were recorded. Following indices were an indication to explore the efficacy and resultant quality of the product.

- Gingival index

- Plaque index

- VAS scale for xerostomia

- VAS scale for desensitization.

According to study conducted in December 2011 by Marchetti et al., ${ }^{7}$ essential oil mouthwash has shown inhibitory effect of plaque regrowth in 3 days. It showed plaque index of 2.18 .

Our study has shown a mean plaque index of 0.292 postoperative as compared to baseline plaque index of 0.669 . Our study has shown greater reduction in plaque regrowth because of the added benefit of propolis.

According to study conducted in May 2011, by Dodwad et al., 8 propolis has reduced symptoms of dentinal hypersensitivity in $50 \%$ of the cases after 1 week and $30 \%$ after 4 weeks.

Our study has shown desensitization index of 1.866 as baseline as compared to postoperative index of 0.533 in case group. However, our study has shown no difference in desensitization index (baseline and postoperative) in control group because of the absence of propolis in control spray. Hence, proving the role of propolis in treatment of dentinal hypersensitivity. 
The effect of propolis could be due to its tubular sealing ability which prevents the flow of dentinal fluid in the tubules, thereby preventing any alteration in the arrangement of their odontoblastic process and nerve endings. The long-lasting effect of propolis probably could be due to stable nature of deposits so formed. ${ }^{9}$
Salivary rate as scored by patient in accordance with VAS scale has shown baseline index of 2.066 and postoperative index of 1.733 . According to study conducted by Atashi et al., ${ }^{10}$ mouth dryness mean score in the intervention (essential oil gel) group was significantly greater than the placebo group $(Z=4.48, p=0.0001)$. In our study we got $Z=-0.459$ and $p=0.646$.

Table 3: Comparison of mean values (baseline and postoperative) of case group

\begin{tabular}{|c|c|c|c|c|c|}
\hline \multicolumn{6}{|c|}{ Wilcoxon signed ranks test (case group) } \\
\hline & $N$ & Mean & $S D$ & $Z$ & $p$ \\
\hline GIBL & 15 & 0.548 & 0.120 & \multirow{2}{*}{-3.429} & \multirow{2}{*}{$0.001 *$} \\
\hline GIPO & 15 & 0.227 & 0.071 & & \\
\hline PIBL & 15 & 0.669 & 0.222 & \multirow{2}{*}{-3.339} & \multirow{2}{*}{$0.001^{*}$} \\
\hline PIPO & 15 & 0.292 & 0.101 & & \\
\hline SPEAKBL & 15 & 2.133 & 0.915 & \multirow{2}{*}{-2.919} & \multirow{2}{*}{$0.004^{*}$} \\
\hline SPEAKPO & 15 & 1.266 & 0.703 & & \\
\hline SWALLOWBL & 15 & 2.066 & 0.883 & \multirow{2}{*}{-3.276} & \multirow{2}{*}{$0.001^{*}$} \\
\hline SWALLOWPO & 15 & 1.133 & 0.516 & & \\
\hline SRBL & 15 & 2.066 & 0.703 & \multirow{2}{*}{-1.667} & \multirow{2}{*}{0.096} \\
\hline SRPO & 15 & 1.733 & 0.593 & & \\
\hline DMBL & 15 & 2.133 & 0.743 & \multirow{2}{*}{-2.810} & \multirow{2}{*}{$0.005^{*}$} \\
\hline DMPO & 15 & 1.400 & 0.507 & & \\
\hline DTBL & 15 & 1.800 & 1.014 & \multirow{2}{*}{-2.251} & \multirow{2}{*}{$0.024^{*}$} \\
\hline DTPO & 15 & 1.200 & 0.560 & & \\
\hline DLBL & 15 & 2.266 & 1.162 & \multirow{2}{*}{-3.066} & \multirow{2}{*}{$0.002^{*}$} \\
\hline DLPO & 15 & 1.200 & 0.414 & & \\
\hline DTOBL & 15 & 2.000 & 1.069 & \multirow{2}{*}{-2.640} & \multirow{2}{*}{$0.008^{*}$} \\
\hline DTOPO & 15 & 1.333 & 0.487 & & \\
\hline DESEZBL & 15 & 1.866 & 0.639 & \multirow{2}{*}{-3.542} & \multirow{2}{*}{$<0.001^{* *}$} \\
\hline DESENPO & 15 & 0.533 & 0.516 & & \\
\hline
\end{tabular}

Table 4: Comparison of mean values (baseline and postoperative) of control group

\begin{tabular}{|c|c|c|c|c|c|}
\hline \multicolumn{6}{|c|}{ Wilcoxon signed ranks test (case group) } \\
\hline & $N$ & Mean & $S D$ & $Z$ & $p$ \\
\hline GIBL & 15 & 0.489 & 0.251 & \multirow{2}{*}{-3.183} & \multirow{2}{*}{$0.001^{*}$} \\
\hline GIPO & 15 & 0.274 & 0.109 & & \\
\hline PIBL & 15 & 0.458 & 0.201 & \multirow{2}{*}{-2.730} & \multirow{2}{*}{$0.006^{*}$} \\
\hline PIPO & 15 & 0.281 & 0.182 & & \\
\hline SPEAKBL & 15 & 1.533 & 0.743 & \multirow{2}{*}{-0.707} & \multirow{2}{*}{0.480} \\
\hline SPEAKPO & 15 & 1.400 & 0.828 & & \\
\hline SWALLOWBL & 15 & 1.866 & 0.915 & \multirow{2}{*}{-0.378} & \multirow{2}{*}{0.705} \\
\hline SWALLOWPO & 15 & 1.800 & 1.082 & & \\
\hline SRBL & 15 & 2.400 & 1.242 & \multirow{2}{*}{-1.040} & \multirow{2}{*}{0.298} \\
\hline SRPO & 15 & 2.066 & 0.961 & & \\
\hline DMBL & 15 & 1.666 & 1.046 & \multirow{2}{*}{-1.508} & \multirow{2}{*}{0.132} \\
\hline DMPO & 15 & 1.333 & 1.046 & & \\
\hline DTBL & 15 & 1.800 & 1.146 & \multirow{2}{*}{-2.070} & \multirow{2}{*}{$0.038^{*}$} \\
\hline DTPO & 15 & 1.200 & 0.861 & & \\
\hline DLBL & 15 & 2.000 & 1.133 & \multirow{2}{*}{-1.933} & \multirow{2}{*}{0.053} \\
\hline DLPO & 15 & 1.533 & 1.125 & & \\
\hline DTOBL & 15 & 1.666 & 1.175 & \multirow{2}{*}{-1.406} & \multirow{2}{*}{0.160} \\
\hline DTOPO & 15 & 1.333 & 1.112 & & \\
\hline DESEZBL & 15 & 0.200 & 0.414 & \multirow{2}{*}{0.000} & \multirow{2}{*}{1.000} \\
\hline DESENPO & 15 & 0.200 & 0.414 & & \\
\hline
\end{tabular}


This evidence guided approach (by formulation of essential oil intraoral spray) for xerostomia management focuses on providing suitable treatment in relieving dry mouth symptoms, dentinal hypersensitivity, reduces oral complications, and improves quality of life. Anxiety and depression (e.g., in students at examination times or in people due to other issues in life) are treated by drugs which are salivary inhibitors so this spray is useful for these patients which will alleviate dry mouth related complications. ${ }^{11-15}$

Also, the spray is packaged in a very small spray bottle which is easy to carry around and use as and when needed.

Hence, the essential oil intraoral spray has all the advantages of promoting oral health by treating xerostomia, dentinal hypersensitivity, and less plaque accumulation, thus, improving the overall health.

\section{Conclusion}

In this study, the essential oil and propolis or placebo were provided in the form of spray to control the daily plaque formation and to make their application easier to be used anywhere and at any time. It is effective in improving oral health of patients suffering from dry mouth, dentinal hypersensitivity. It also ensured better patient compliance as it gives a feeling of fresh mouth hence encouraging them to use as prescribed.

\section{References}

1. Sbordone L, Bortolaia C. Oral microbial biofilms and plaque-related diseases: microbial communities and their role in the shift from oral health to disease. Clin Oral Investig 2003;7(4):181-188. DOI: 10.1007/s00784-003-0236-1

2. Vlachojannis C, Chrubasik-Hausmann S, Hellwig E, et al. A preliminary investigation on the antimicrobial activity of Listerine ${ }^{\oplus}$, its components, and of mixtures thereof. Phytother Res 2015;29(10):1590-1594. DOI: 10.1002/ptr.5399

3. Charles $\mathrm{CH}$, Sharma NC, Galustians HJ, et al. Comparative efficacy of an antiseptic mouthrinse and an antiplaque/antigingivitis dentifrice: a six-month clinical trial. J Am Dent Assoc 2001;132(5):670-675. DOI: 10.14219/jada.archive.2001.0245

4. Fine $\mathrm{DH}$. Mouthrinses as adjuncts for plaque and gingivitis management. A status report for the American Journal of Dentistry. Am J Dent 1988;1(6):259-263.

5. Barnett ML. The role of therapeutic antimicrobial mouthrinses in clinical practice: control of supragingival plaque and gingivitis. J Am Dent Assoc 2003;134(6):699-704. DOI: 10.14219/jada.archive.2003.0255

6. Bakhtiari S, Azimi HS, Esfandiari F, et al. Comparison of the effect of sugarfree orbit chewing gum \& natural turpentine on salivary flow rate \& $\mathrm{pH}$

7. Marchetti E, Mummolo S, Di Mattia J, et al. Efficacy of essential oil mouthwash with and without alcohol: a 3-day plaque accumulation model. Trials 2011;12(1):1-7. DOI: 10.1186/1745-6215-12-262

8. Purra AR, Mushtaq M, Acharya SR, et al. A comparative evaluation of propolis and $5.0 \%$ potassium nitrate as a dentine desensitizer: a clinical study. J Indian Soc Periodontol 2014;18(4):466. DOI: 10.4103/0972-124X.138695

9. Atashi V, Yazdannik A, Mahjobipoor H, et al. The effects of Aloe vera-Peppermint (Veramin) moisturizing gel on mouth dryness and oral health among patients hospitalized in intensive care units: a triple-blind randomized placebo-controlled trial. J Res Pharm Pract 2018;7(2):104. DOI: 10.4103/jrpp.JRPP_18_21

10. Plemons JM, Al-Hashimi I, Marek CL. Managing xerostomia and salivary gland hypofunction: executive summary of a report from the American Dental Association Council on Scientific Affairs. J Am Dent Assoc 2014;145(8):867-873. DOI: 10.14219/jada.2014.44

11. Sivapathasundharam B. Shafer's Textbook of Oral Pathology-E Book. Elsevier Health Sciences 2016.

12. Neville BW, Damm DD, Allen CM, et al. Oral and maxillofacial pathology. Elsevier Health Sciences 2015.

13. Hu J, Andablo-Reyes E, Mighell A, et al. Dry mouth diagnosis and saliva substitutes: a review from a textural perspective. J Texture Stud 2021;52(2):141-156. DOI: 10.13039/100010663

14. Guggenheimer J, Moore PA. Xerostomia: etiology, recognition and treatment. J Am Dent Ass 2003;134(1):61-69. DOI: 10.14219/jada. archive. 2003.0018

15. Fischman SL, Aguirre A, Charles CH. Use of essential oil-containing mouthrinses by xerostomic individuals: determination of potential for oral mucosal irritation. Am J Dent 2004;17(1):23-26. 